\title{
Are there optical differences between storm-time substorms and isolated substorms?
}

\author{
R. A. Hoffman ${ }^{1}$, J. W. Gjerloev ${ }^{2}$, L. A. Frank ${ }^{3}$, and J. W. Sigwarth ${ }^{1}$ \\ ${ }^{1}$ Heliophysics Science Division, NASA/Goddard Space Flight Center, Greenbelt, MD 20771, USA \\ ${ }^{2}$ Applied Physics Laboratory, Johns Hopkins University, Laurel, MD 20723, 0771, USA \\ ${ }^{3}$ The University of Iowa, Department of Physics and Astronomy, Iowa City, IO, 52242, USA
}

Received: 5 November 2009 - Revised: 25 March 2010 - Accepted: 17 May 2010 - Published: 28 May 2010

\begin{abstract}
We have performed an extensive analysis of auroral optical events (substorms) that occurred during the development of the main phase of magnetic storms. Using images from the Earth Camera on the Polar spacecraft (Frank et al., 1995), we compared the optical emission features of substorms occurring during 16 expansion phases of magnetic storms with the features of isolated substorms occurring during non-storm times. The comparison used two techniques, visual inspection and statistical comparisons. The comparisons were based on the common characteristics seen in isolated substorms that were initially identified by Akasofu (1964) and quantified by Gjerloev et al. (2008). We find that when auroral activity does occur during main phase development the characteristics of the aurora are very dissimilar to those of the classical isolated substorm. The primary differences include the lack of a surge/bulge, lack of bifurcation of the aurora, much shorter expansion phases, and greater intensities.

Since a surge/bulge and bifurcation of the aurora are characteristics of the existence of a substorm current wedge, a key component of the magnetosphere-ionosphere current system during substorms, the lack of this component would indicate that the classical substorm model does not apply to the storm time magnetosphere-ionosphere current system. Rather several of the analyses suggest that the storm-time substorms are associated more closely with the auroral oval, at least spatially, and, therefore, probably with the plasma sheet dynamics during the main phase development. These results then must call into question the widely held assumption that there is no intrinsic difference between storm-time substorms and classical isolated substorms.
\end{abstract}

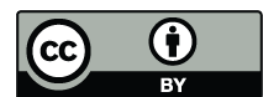

Correspondence to: J. W. Gjerloev (jesper.gjerloev@jhuapl.edu)
Keywords. Magnetospheric physics (Auroral phenomena; Magnetosphere-ionosphere interactions; Storms and substorms)

\section{Introduction}

Kan (2006) recently summarized the status of the issue of storm-substorm relationships in a report of the StormSubstorm Relations Workshop in Banff, Albert, Canada. The consensus position seemed to accept the conclusion of Kamide (1992) that substorms are not a necessary condition for the occurrence of a magnetic storm. This conclusion evolved over several decades of study from the original hypothesis by Chapman (1962) that "a magnetic storm consists of sporadic and intermittent polar disturbances" that "I call polar substorms", which "appear also during rather quiet periods".

The optical or auroral manifestations of polar disturbances were organized in the seminal study of IGY all-sky camera photographs by Akasofu (1964) from which he defined the auroral substorm, with specific phases and characteristics (see Gjerloev et al., 2007, for a quantification of the macroscale characteristics). Several years later he proposed the concept of the magnetospheric substorm, or the polar magnetic substorm (Akasofu, 1968), whose manifestations included the auroral (optical) substorm and simultaneously ordered ground magnetic perturbations. Subsequently McPherron et al. (1970) added the growth phase. With the addition of magnetospheric measurements from spacecraft (primarily at synchronous altitude) during ground-based optical and magnetic perturbation measurements (e.g., see Kan, 1991), concepts of the term substorm became generalized to include any "transient process initiated on the nightside of the earth in

Published by Copernicus Publications on behalf of the European Geosciences Union. 
which a significant amount of energy derived from the solar wind-magnetosphere interaction is deposited in the auroral ionosphere and magnetosphere" (Rostoker et al., 1980). This statement remains perhaps the most inclusive and generally accepted description of the term substorm and we adopt it for this analysis.

While the existence of multiple substorms is no longer considered a necessary condition for the development of magnetic storms (e.g., Kamide, 1992; McPherron, 1997), their role in magnetic storms is still not clear. One thought is that transient electric fields associated with substorms may help trap plasma carried from the tail into the ring current by the global electric field, which in a static field would drift out the dayside magnetopause (McPherron, 1997). This type of concept must assume that the magnetospheric electrodynamics of the substorm occurring during the main phase development of the magnetic storms are comparable to those of isolated substorms (Kamide, 1992), since it is the electrodynamics of the isolated substorm that has received primary study. In fact, Kamide (1992) stated explicitly that: "There is no intrinsic difference between storm time substorms and usual substorms", a concept repeated by Gonzalez et al. (1994) in a review paper on magnetic storms.

In the ionosphere/thermosphere region the isolated substorm shows specific characteristics, not only in the optical emission patterns, but also in the patterns of the conductivities, electric field, ionospheric currents, and field-aligned currents (e.g., Kan et al., 1991; Fujii et al., 1994; Kamide et al., 1996; Gjerloev and Hoffman, 2000, 2002). However, to our knowledge, the comparability of the electrodynamics of isolated substorms and storm-time substorms has never been observationally proven. In fact, when Baumjohann et al. (1996) compared tail magnetic signatures during isolated substorms and storm-time "substorms" they found considerable differences. While they raised the question whether there are two types of substorms, they suggested that they could have different physical processes in the magnetosphere, but yet could still show the same aurora and electrodynamics in the ionosphere. The dubious basis for the conclusion that the two types of events have no apparent differences in the ionosphere suggests that additional investigations on the commonality of the electrodynamics might be of value. We argue that if we find an electrodynamic parameter during storm-time events that has different characteristics than during isolated events, it would not be appropriate to assume that the remaining electrodynamic characteristics are the same as the electrodynamic characteristics of isolated substorms.

To initiate an investigation of this assumption of commonality, we initially take a perspective of the substorm-storm relationship based solely on optical observations. We will compare the optical signatures of substorms that occurred during the development of the main phase magnetic storm with the optical signatures of the isolated substorm as defined by Akasofu (1964) and subsequently observed and quantified by global auroral images (Fujii et al., 1994; Gjerloev et al., 2007). Two types of comparative analyses will be performed, a detailed visual comparison and a statistical comparison. Gjerloev et al. (2007) found that the Akasofu-type substorm is by far the predominant type of large-scale isolated auroral event during non-magnetic storm periods. After excluding pseudo-breakups and pressure pulse auroras, their analysis found 116 substorms after having to discard only about 20 additional events that did not display the classical characteristics. While these latter events would also be classified as substorms under the currently accepted definition (Rostoker et al., 1980), we will use the term "isolated substorm" to refer to the 116 events that displayed the Akasofu-type characteristics. However, in spite of the fact that the optical signatures of these 116 events had large variations in their locations and temporal development, Gjerloev et al. (2007) found that the auroral emission patterns of the individual substorms could be normalized temporally and spatially to an average substorm pattern with surprisingly high correlation coefficients.

We do point out that this approach is a partial perspective of whether the electrodynamics of the isolated substorm also pertains to the substorms during the storm main phase, since global auroral images only provide indications of the locations of electron (and proton) precipitation and the resulting patterns of ionospheric conductivity (Germany et al., 1994). However, we showed that this normalization success enabled the development of normalized patterns of the convection electric field and field-aligned currents for the isolated substorms (Fujii et al., 1994; Gjerloev and Hoffman, 2001, 2002).

We emphasize that this analysis does not use any ground magnetic data to identify storm-time auroral events. Only Sym- $\mathrm{H}$ is used to mark the onset time of the main phase storm and the time of minimum in Sym-H, providing the time periods of our study, so accuracy issues of the ring current parameters are of no consequence (Ohtani et al., 2005).

\section{Data from storm-times}

The primary imaging data used in this study came from the Earth Camera (EC) images acquired by the Visible Imaging System (VIS) on the Polar spacecraft (Frank et al., 1995). This camera provided global auroral images in the far ultraviolet (FUV) range of $\sim 124-149 \mathrm{~nm}$ in contrast to the more limited views but higher spatial resolution from its visible imaging camera. The ultraviolet images allowed the observation of the auroral oval into regions of some sunlight contamination, but since we required the most significant portion of the oval for each storm to be observed with reasonable aspect, our data are heavily biased towards the winter months. All observations were of the Northern Hemisphere. These data were supplemented by the $557.7 \mathrm{~nm}$ visible images from VIS that operated only during the winter months, so about half the storms had useable visible images. While 
Table 1. Coverage by global auroral images of main phase development for 16 storms. Times are in decimal hours.

\begin{tabular}{|c|c|c|c|c|c|c|c|c|}
\hline \multirow[t]{2}{*}{ Event } & \multirow{2}{*}{$\begin{array}{c}\text { Delta } \\
\text { Sym-H }\end{array}$} & \multirow{2}{*}{$\begin{array}{c}\text { Sym-H } \\
\text { Onset }\end{array}$} & \multirow{2}{*}{$\begin{array}{c}\text { Sym-H } \\
\text { Minimum }\end{array}$} & \multirow{2}{*}{$\begin{array}{l}\text { Duration } \\
\text { (h) }\end{array}$} & \multicolumn{2}{|c|}{ Images } & \multicolumn{2}{|c|}{ Normalized } \\
\hline & & & & & Start & End & Start & End \\
\hline $97 / 121$ & 85 & 16.78 & 24.16 & 7.38 & $<$ onset & 19.50 & $<0.00$ & 0.37 \\
\hline $97 / 246$ & 100 & 18.37 & 22.00 & 3.63 & $\begin{array}{r}<\text { onset } \\
20.47\end{array}$ & $\begin{array}{l}20.18 \\
03.00\end{array}$ & $\begin{array}{r}<0.00 \\
0.58\end{array}$ & $\begin{array}{r}0.50 \\
>1.00\end{array}$ \\
\hline $97 / 274$ & 108 & 04.63 & 15.86 & 11.23 & $<$ onset & 08.85 & $<0.00$ & 0.37 \\
\hline $97 / 283$ & 120 & 17.45 & 26.92 & 9.47 & $<$ onset & 23.80 & $<0.00$ & 0.67 \\
\hline $97 / 344$ & 60 & 10.44 & 19.73 & 9.29 & $<$ onset & 15.08 & 0.00 & 0.60 \\
\hline $97 / 364$ & 68 & 02.77 & 18.75 & 15.98 & 03.42 & 15.00 & 0.04 & 0.76 \\
\hline 98/006 & 82 & 15.33 & 27.15 & 11.82 & $<$ onset & 24.60 & 0.00 & 0.78 \\
\hline 98/029 & 58 & 21.68 & 36.37 & 14.69 & $\begin{array}{r}<\text { onset } \\
06.67\end{array}$ & $\begin{array}{r}23.60 \\
>\mathrm{MIN}\end{array}$ & $\begin{array}{r}<0.00 \\
0.61\end{array}$ & $\begin{array}{r}0.13 \\
>1.00\end{array}$ \\
\hline 98/048 & 120 & 12.70 & 24.78 & 12.08 & $\begin{array}{r}\sim 18.00 \\
24.03\end{array}$ & $\begin{array}{r}23.63 \\
>\mathrm{MIN}\end{array}$ & $\begin{array}{r}\sim 0.44 \\
0.94\end{array}$ & $\begin{array}{r}0.90 \\
>1.00\end{array}$ \\
\hline 98/069 & 120 & 15.82 & 18.05 & 2.23 & $<$ onset & $>\mathrm{MIN}$ & $<0.00$ & $>1.00$ \\
\hline $98 / 114$ & 72 & 01.28 & 07.52 & 6.24 & $<$ onset & $>\mathrm{MIN}$ & $<0.00$ & $>1.00$ \\
\hline $98 / 238$ & 175 & 09.75 & 33.00 & 23.25 & $\begin{array}{r}<\text { onset } \\
22.5\end{array}$ & $\begin{array}{l}11.50 \\
28.67\end{array}$ & $\begin{array}{l}0.00 \\
0.56\end{array}$ & $\begin{array}{l}0.08 \\
0.82\end{array}$ \\
\hline $98 / 268$ & 225 & 01.53 & 06.85 & 5.32 & $<$ onset & 04.00 & $<0.00$ & 0.46 \\
\hline $99 / 059$ & 94 & 17.75 & 25.35 & 7.60 & 21.33 & $>\mathrm{MIN}$ & 0.47 & $>1.00$ \\
\hline $99 / 106$ & 111 & 23.05 & 28.32 & 5.27 & $<$ onset & $>\mathrm{MIN}$ & $<0.00$ & $>1.00$ \\
\hline $99 / 346$ & 85 & 18.58 & 33.00 & 14.42 & 24.00 & 32.07 & 0.38 & 0.93 \\
\hline
\end{tabular}

the visible images were limited in spatial extent, they had seven times the spatial resolution, making them valuable for verifying the interpretation of the EC images. Unfortunately, the various VIS cameras had to share the same telemetry allocation, so the EC temporal resolution decreased from one image per minute to about one every five minutes when the visible cameras were active. To recover the higher time resolution, especially to obtain the onset times of events and to assure continuity in development, we supplemented the VIS data with images from the Ultraviolet Imaging system (UVI) (Torr et al., 1995). For our analysis we preferred to use the VIS data over the UVI data because of its global coverage and increased spatial accuracy. Due to an imbalance of the Polar spacecraft apparently resulting from an in- complete erection of one of the spacecraft masts following launch, the spacecraft attained a slight wobble, which significantly smeared the acquisition of the optical data in one direction. The VIS data acquisition scheme was able to be modified in flight to eliminate most of this smearing (Frank and Sigwarth, 1997).

Using images from several imaging systems does introduce concern over the different response functions of the imagers and the different color scales used in the displays. Fortunately the $557.7 \mathrm{~nm}$ visible images and the ultraviolet images respond primarily to similar electron energies, both in the keV region. Since the UVI data supplemented the EC data, allowing a qualitative normalization between the data sets during an event, and were used primarily for timing 


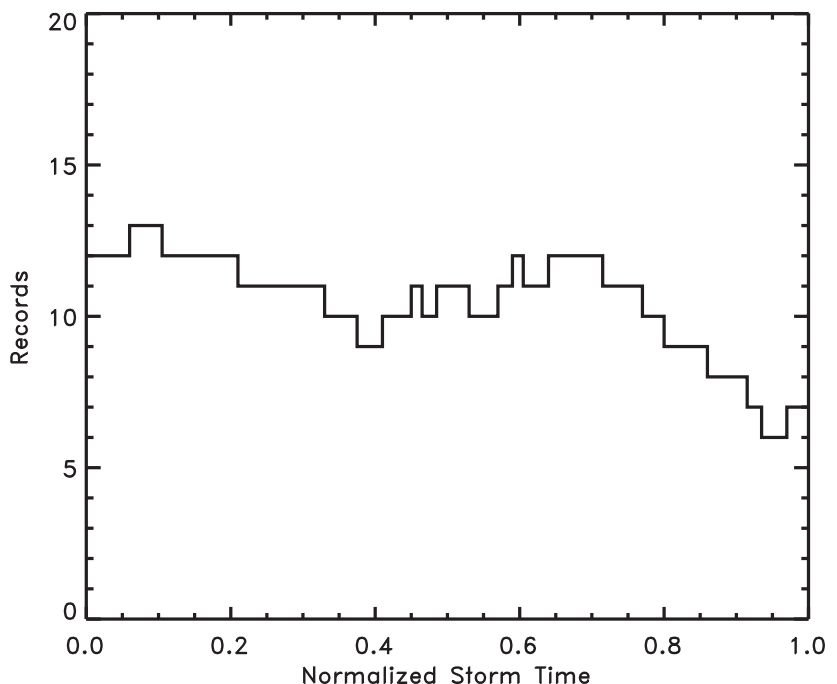

Fig. 1. Number of magnetic storms with auroral imaging as a function of normalized time during storm main-phase development, with $T=0$ when Sym-H begins to decrease to $T=1$ at Sym-H minimum.

determinations and not spatial locations, any impacts of the differences in the data sets were minimized.

Sixteen magnetic storms during 1997 through 1999 were selected for inclusion in this study (Table 1). Criteria for selection included Sym-H minimum of at least $-50 \mathrm{nT}$, a decrease in Sym-H from onset without considerable recovery before reaching its minimum, and a single Sym-H minimum or an end to the period of study at the first minimum. Our set of storms contained many selected by Wu et al. (2004) in their study of "substorms" within storms, though their size criterion was Dst $<30 \mathrm{nT}$, were associated only with magnetic clouds, and included the storm recovery phase. We did not use the storm shown as their example (their Figs. 1 and 3) because of the near recovery of Sym-H part way through the event. Most of the storms used in this study had a main phase between -60 and $-120 \mathrm{nT}$, with two considerably larger at 175 and one at $225 \mathrm{nT}$. Main phase development times ranged from $2.25 \mathrm{~h}$ to nearly an entire day.

For some of the statistical analyses of this study it is important that coverage of the main phase development by auroral imaging be relatively uniform from onset to Sym- $\mathrm{H}$ min and with a sufficient number of events to draw generalized conclusions. Coverage from the 16 storms can be tested by normalizing storm time $T$ for each storm between 0 and 1 from onset to Sym-H min. and counting the number of storms having auroral coverage as a function of $T$. Coverage for each storm is listed in Table 1 with the sum as a function of time $T$ shown in Fig. 1. Time from onset $T=0$ to $T=$ almost 0.8 has 10 storms or more, but falls off to seven towards Sym-H min, still an adequate number for our purposes.

\section{Storm-time substorm selection}

The selection of an auroral optical event to be included in this study, or substorm per the Rostoker et al. (1980) definition, was based only on its optical characteristics that could be identified in the EC images:

- Onset during the expansion phase of a selected magnetic storm;

- An onset distinguishable from any existing auroras, but not necessarily localized ("point source"), as we required for isolated substorms (Gjerloev et al., 2008);

- Expansion in area;

- Brightening of the aurora during expansion;

- Maximum in area/intensity;

- Decay in intensity (but our analysis ends at the maximum);

- At least the expanded region in darkness, and preferably most of the oval;

- A new event distinguished from an ongoing event if the two are clearly separated in magnetic local time, allowing two events to overlap in time.

We did not establish any quantitative threshold for the stormtime substorms, so we may not be totally self-consistent in the inclusion of smaller events. There were many weak and short-lived optical brightenings during the magnetic storm main phases that are not included. Since small, short events are not comparable temporally to isolated substorms, their neglect is not pertinent to our analyses. If a re-brightening leading to a new maximum occurred in the same MLT region as a maximum, provided there was not a considerable decay, the two brightenings were considered a single event. We identified 54 events that had acceptable image coverage during the portions of the 16 storms.

From the images of a substorm, we determined the onset time and the maximum time. If onset appeared to be localized (see Gjerloev et al., 2008, for examples), we measured the MLT and invariant latitude of the center of the area. While we record the values to the nearest tenth of an hour in MLT and $0.5^{\circ}$ in ILat the accuracies highly depend on the event characteristics. From the maximum image, if a surge were distinguishable from the auroral oval (a bifurcation), we measured the locations of the west and east ends of the surge/bulge aurora, the maximum latitude of any emissions, and the MLT of the west and east ends of the oval auroral emissions (see Gjerloev et al., 2008, for methodology). For events without sufficient bifurcation we measured the MLT and ILat of the west and east ends of the total emission region associated with the event. 


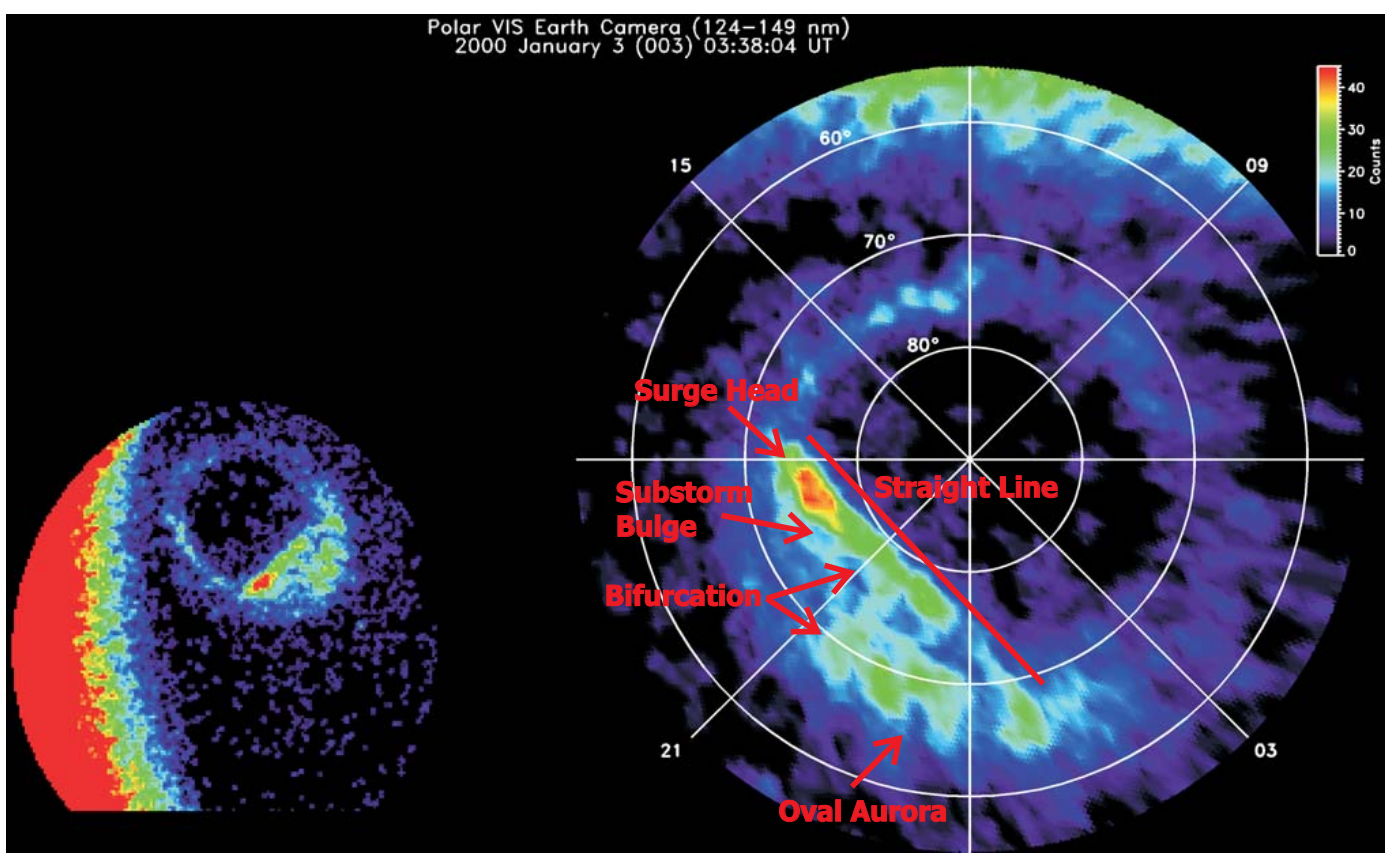

Fig. 2. A good example of an isolated classical auroral substorm event at the maximum of the expansion phase (from Gjerloev et al., 2007, Fig. 1), the original image on the left and a mapping to a magnetic local time (MLT), invariant latitude (ILat) coordinate system on the right. Key characteristics are labeled. Onset location was 69.0 ILat and 21.6 MLT at 03:09 UT.

The accuracy to which we can select these positions depends, of course, on the gradients in the emissions. We generally used as the boundary the transition from the purple to the medium blue color seen, for example, as a lining along the eastern edge of the brightening that ends around 1.5 MLT in Fig. 3f. Viewing the sequence of images helps define these positions, especially the end points. The selections are sufficiently accurate for the purpose of the analysis.

\section{Comparisons}

Two comparative techniques were employed to determine whether substorms occurring during magnetic storm main phases had common characteristics with isolated substorms, a visual comparison and a statistical comparison.

\subsection{Visual comparisons}

We first identify the optical characteristics of the isolated substorm that will be used for comparison. To illustrate we show a good example of an isolated substorm in Fig. 2 (from Gjerloev et al., 2007, Fig. 1). The characteristics are based on the commonalities identified by Akasofu (1964) and quantified by Gjerloev et al. (2008). They include the following:

- An emission region (bulge) that arose in latitude out of the auroral oval

- Bifurcation, separating the bulge aurora from the oval aurora
- A surge head

- Oval aurora offset to the east in MLT from the bulge aurora

- A straight-line poleward boundary (seen best in original image), resulting in the highest latitude of the aurora near its center in MLT (caused by the bulge)

In performing our analysis we immediately realized that the substorms that occurred during the expansion phases of magnetic storms displayed a large gamut of characteristics unlike those found in the isolated bulge-type auroral substorm. As a result, for our visual comparisons we show the types of optical signatures encountered and identify how they are different from the characteristics of the isolated substorm.

All the following examples of events during the main phase development are taken at the maximum of each event. The first example, Fig. 3a, is a classical-looking bulge-type substorm that expanded poleward out of the auroral oval (onset was in a short data gap but likely located at an ILat of about $62^{\circ}$, somewhat after 21:00 MLT). It is characterized by a bifurcation of the optical emissions, giving a rather large total emission region in MLT $(6 \mathrm{~h})$ and latitude width $\left(12^{\circ}\right.$ invariant latitude), brightenings along the poleward edge and especially at the western head of the expanded region (surge), and a straight-line poleward boundary. The locations of the surge head and the bulge east end are identifiable. This is the best example of a substorm displaying the Akasofu (1964) characteristics during storm development. Of the 54 

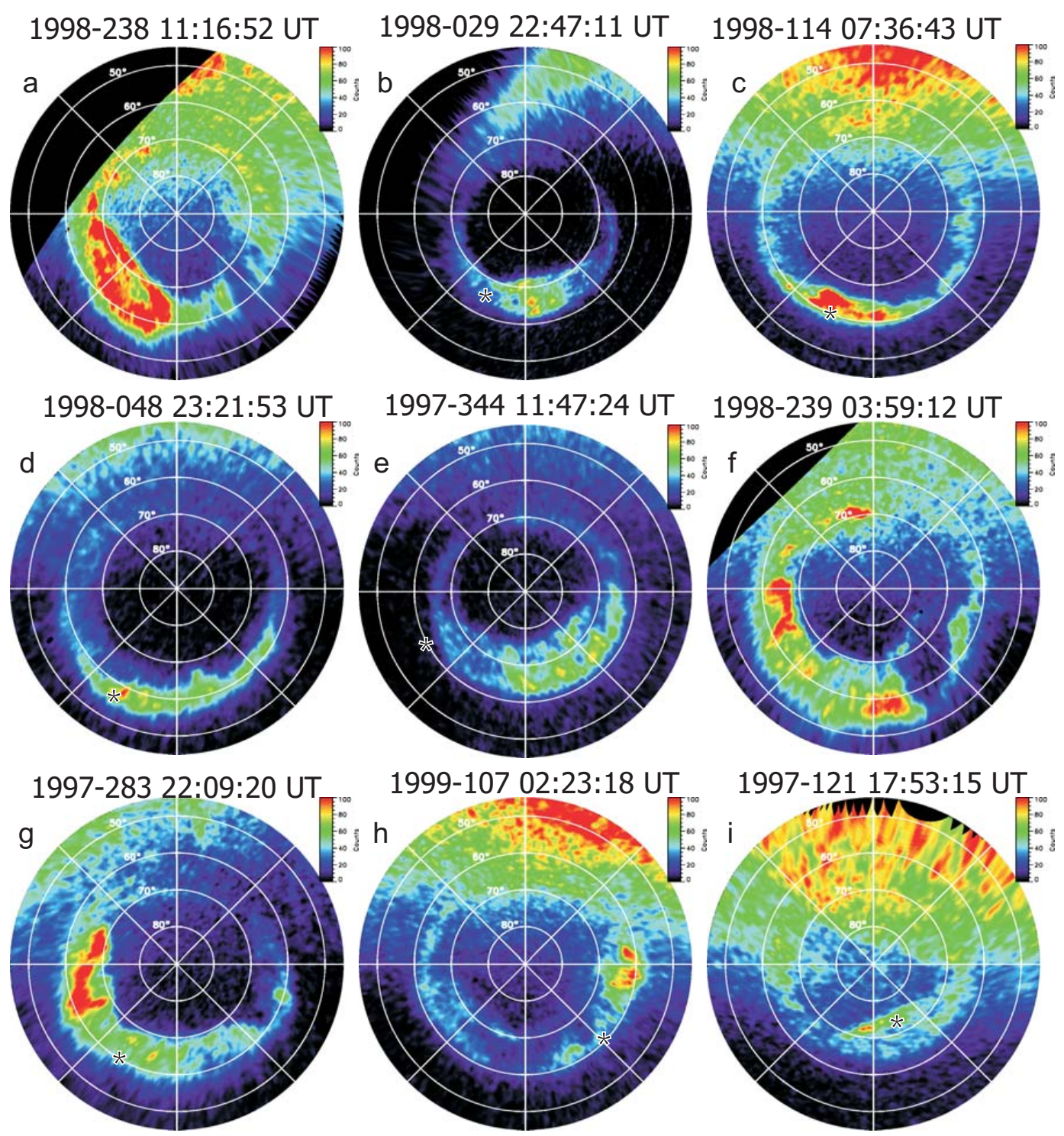

Fig. 3. Examples of auroral events during magnetic storm main phase development. All the images have the same color scale, 0 to 100 counts per pixel. The images have been transformed to a MLT, ILat map with the sun at the top. The onset location, if local, is marked by an asterisk. (a) Best example of a classical bulge-type substorm; (b) an auroral oval brightening of very limited local time extent; (c) a more common auroral oval brightening; (d) a very distributed oval brightening, almost $9 \mathrm{~h}$ in length at very low latitudes; (e) a large event with a very high latitude boundary; (f) a huge event both in local time and latitude coverage; (g) a dusk-side event; (h) a dawn side event; (i) a polar arc brightening.

events in this study, only $12(22 \%)$ allowed the measure of the surge/bulge positions compared to $85 \%$ for isolated substorms. Many of these events did not develop out of a localized onset like an isolated substorm, but eventually evolved to show a bulge whose ends could be identified. Of the twelve, only seven (13\%) could be considered to have the characteristics of the isolated substorm for various reasons.

The next three images are examples of the most common type of event during a main-phase development, the brightened auroral oval, which makes up about $70 \%$ of the events. The event shown in Fig. $3 \mathrm{~b}$ is minimal in extent, like three hours, which we have dubbed a blob. All of the expansion was eastward of the onset point and shows none of the isolated substorm characteristics. Figure $3 \mathrm{c}$ is a more typical brightened oval aurora that expanded a total of about five hours MLT east and west and a number of degrees poleward from the onset point. Note that it shows no surge head, bifurcation, or straight poleward boundary, so lacks the characteristics of an isolated substorm. In these two examples almost all the aurora was poleward of $60^{\circ}$ ILat. Figure $3 \mathrm{~d}$ contains an example of a large MLT expansion, covering about eight hours of MLT, mostly to the east of the onset point. This 


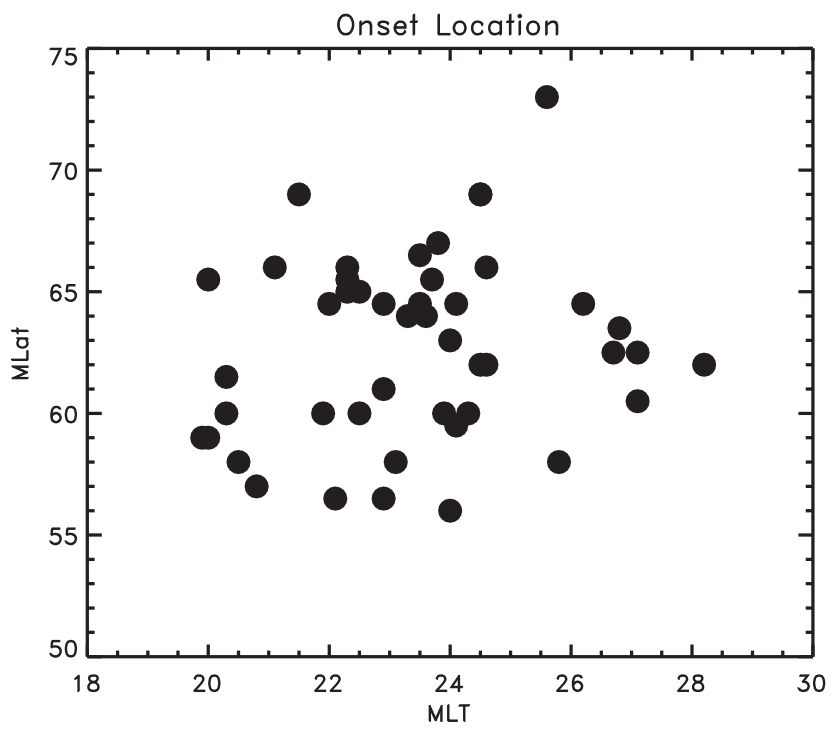

Fig. 4a. Locations in MLT/ILat coordinates of onsets for stormtime substorms having localized onsets.

type of event usually developed out of a very quiet and fairly narrow oval. Note the exceptionally low latitude location of the onset, with most of the ensuing pre-midnight aurora below $60^{\circ}$ ILat. It shows none of the characteristics of the bulge-type substorm. These three examples of the brightened oval aurora type of substorm do not show a development of a surge/bulge that rises in latitude out of the auroral oval and thus do not display any bifurcation or any other characteristic of the isolated substorm.

Next we show an event with an exceptionally high latitude boundary, extending to about $77^{\circ} \mathrm{ILat}$, but with a vague highlatitude cut-off (Fig. 3e). It is composed of several rather north-south structures with weak emissions to the west but lacks the continuous high latitude boundary of a bulge. In total, the brightenings extend almost $12 \mathrm{~h}$ in local time. This is the most extensive example of this type of aurora. The next example is a huge event, both in local time and latitude extent (Fig. 3f). The brightenings extend from about 1.5 MLT, the east end, through dusk to noon, and from $50^{\circ}$ to $70^{\circ}$ in latitude near midnight. Note that neither of these large events shows any of the characteristics of an isolated substorm.

Occasionally substorm emissions expanded and rapidly drifted to the west or east well past their onset MLT (9\%). An intense dusk substorm appears in Fig. 3g with expansion well past 18:00 MLT towards noon. In following the development of this event one could argue that multiple brightenings occurred with the last near dusk at the maximum of the event. In contrast the west, trailing end of the dawn event in Fig. 3h drifted entirely past the onset spot by three hours. Again, in neither type of substorm did the aurora bifurcate.

A rare event that appears something like a classical substorm at its maximum, because it contains an apparent surge

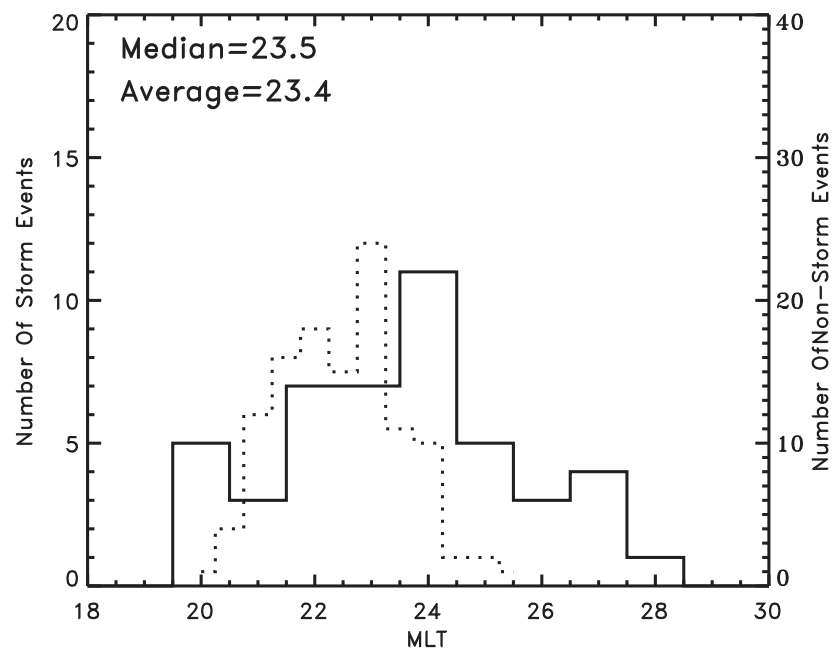

Fig. 4b. Histogram of onset locations as a function of MLT. Superimposed is a similar histogram for isolated substorms (from Gjerloev et al., 2007).

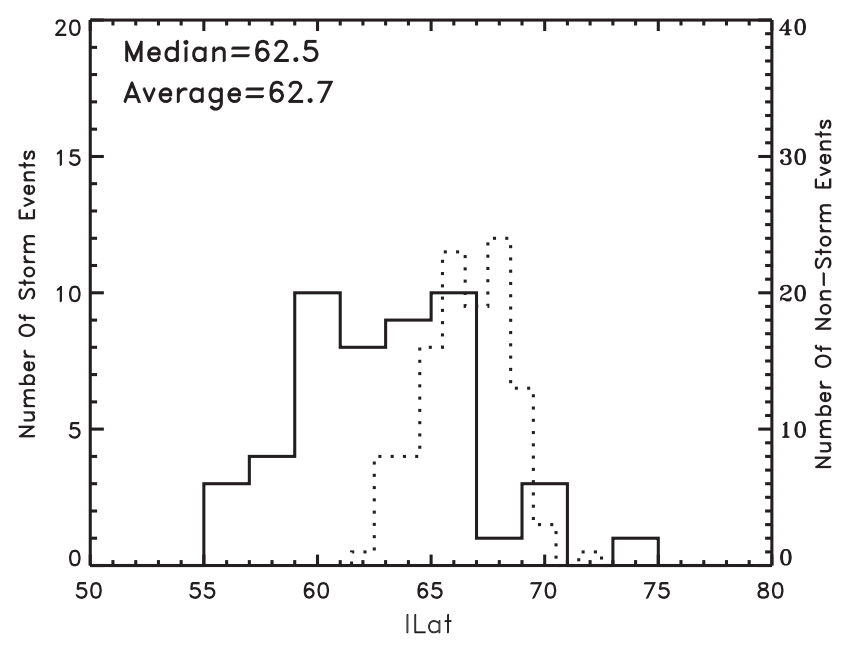

Fig. 4c. Histogram of onset locations as a function of ILat. Superimposed is a similar histogram for isolated substorms (from Gjerloev et al., 2007).

head and a straight poleward boundary, is shown in the final figure (Fig. 3i). However, note that the onset point was at $72^{\circ}$ ILat, whereas all the other onsets were below $65^{\circ}$. Further, the aurora in the oval latitude region faded as the polar boundary aurora brightened. This was merely a brightening of a polar boundary arc.

Other events showed variations from the examples shown in Fig. 3. But all these events (except that in Fig. 3a) clearly lack even some of the characteristics of the classical isolated auroral substorm. 


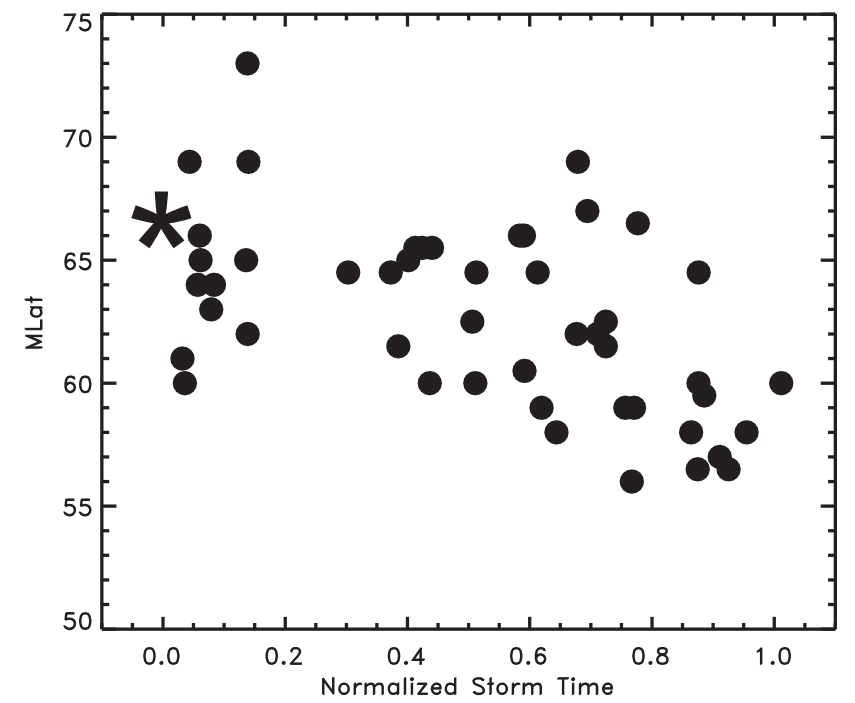

Fig. 5a. ILat locations of localized onsets as a function of normalized storm time. Asterisk indicates the average onset location for isolated substorms.

\subsection{Statistical comparisons}

From the measurements made on the spatial characteristics of each substorm selected during magnetic storm main phases we performed statistical comparisons with the characteristics of isolated substorms (Gjerloev et al., 2007). Comparisons could be made for onset locations, time of the expansion phase, and spatial expansions both in local time and latitude. Comparisons are made both between the distributions of these parameters and their median values.

\subsubsection{Onset plots}

We initially compare the distributions of locations of the onset (if localized onset) with distributions for isolated substorms. Forty-four of the 54 events (about 80\%) were considered to have localized onsets. First we plot the locations in ILat as a function of MLT (Fig. 4a) for storm events. The data show considerable scatter with no apparent relationship. The histograms of the distributions in MLT and ILat are shown in Fig. $4 \mathrm{~b}$ and $\mathrm{c}$ with similar histograms superposed for isolated substorms (dotted). Neither of the storm event distributions could be meaningfully fit with a Gaussian distribution as we did for the isolated substorms (Gjerloev et al., 2007). The median of the MLT distribution for storm-time substorms is about an hour later than for isolated substorms, 23.5 MLT compared to 22.4 MLT. The distribution is somewhat symmetric around midnight and very broad ( $\pm 4 \mathrm{~h}$ MLT) in comparison to the distribution for isolated substorms, which is almost entirely prior to midnight and covers only about $4 \mathrm{~h}$ in total in MLT. The entire distribution is shifted considerably to lower latitudes, extending from $55.5^{\circ}$ to $71^{\circ}$, with a median of $62.5^{\circ}$, over three degrees lower. Since it is well known

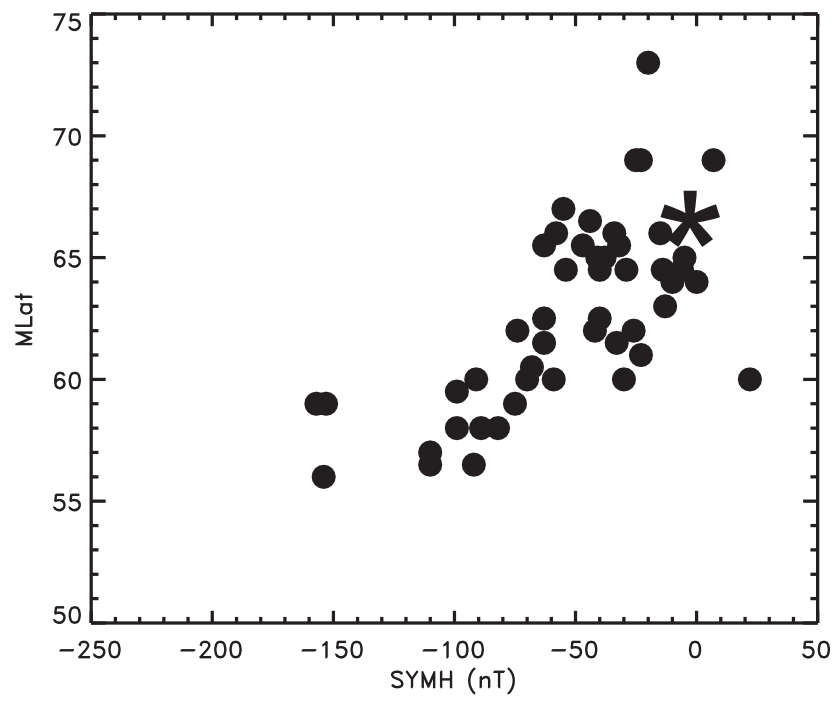

Fig. 5b. ILat locations of localized onsets as a function of Sym$\mathrm{H}$ at the time of event onset. Asterisk indicates the average onset location for isolated substorms.

that the auroral oval moves equatorward as the storm develops (Feldstein and Starkov, 1967; Sheehan and Carovillano, 1978; Tverskaya et al., 1989), we next investigated whether a shift in onset latitudes also occurred, first by plotting the ILat of onset as a function of normalized storm time (Fig. 5a). In spite of the large scatter in points, there appears to be some trend towards lower latitude, with most of the shift after $T=0.5$. However, if the onset latitude is plotted as a function of Sym-H at the time of the substorm onset (Fig. 5b), there is quite a clear trend towards lower latitudes as a function of ring current strength.

All onsets occurred within the pre-event oval. Nearly half of the onsets occurred when the background auroral oval was quiet and weak, and nearly half when there was some type of activity, ranging from bright, small blobs, a narrow, bright oval (arc as seen in the visible imager) to a long existing, fat, active oval. The remaining few events occurred during the decay of a previous event or arose at another MLT from the ongoing event.

\subsubsection{Development from onset to maximum}

The time for development from onset to maximum is next plotted in Fig. 6 as a histogram and superposed on the development time for isolated substorms (from Gjerloev et al., 2007, Fig. 4). The differences in both the distribution and median development time are striking, the latter being only $15 \mathrm{~min}$, half that for isolated substorms (see Table 2). Note that the lowest bar of the histogram is comparable to the temporal resolution of the images and thus the ability to track the development of an event.

Following the analysis of Wu et al. (2004, Fig. 4), we plot in histogram format the number of substorm onsets relative 


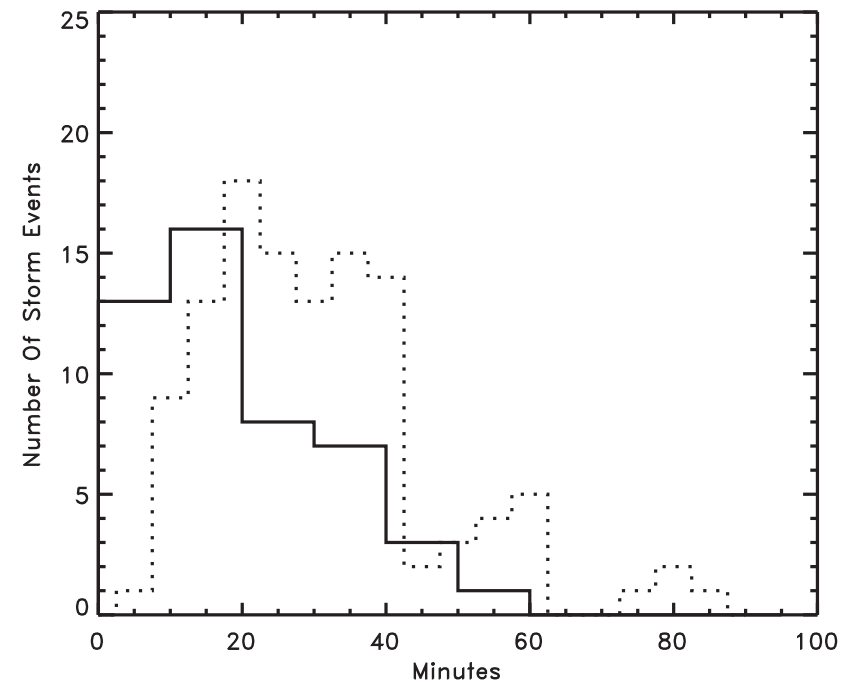

Fig. 6. Histogram of the length of expansion phases for auroral events during the development of the magnetic storm main phase (solid lines). Superimposed as dotted lines is a histogram for expansion phases for isolated substorms (from Gjerloev et al., 2007).

to the time of Sym-H minimum (Fig. 7a), and likewise find that most onsets occurred within the $10 \mathrm{~h}$ prior to Sym-H minimum. (They used Dst min. and binned in 10-h intervals.) The results of $\mathrm{Wu}$ et al. would be expected irrespective of any relationship between substorms and time into a main phase development, since short developing main phases would have all their substorms much closer to Dst minimum than long developing storms. Half of our main phase development times were less than $10 \mathrm{~h}$. However, when we plot in Fig. $7 \mathrm{~b}$ the onset times as a function of normalized storm time, and also normalized to the storm-time coverage (Fig. 1), we no longer observe this relationship. Instead we find a curious cluster of onsets within 0.20 normalized time after the onset of the Sym-H decrease followed by a complete lack of events for the next 0.10. A detailed look at this initial cluster of events shows that no event had its onset simultaneous with the onset of Sym-H decrease, but the cluster occurred between 0.03 to 0.14 in normalized time, with no further event until 0.32. Further investigations of this curious phenomenon, if statistically real, are beyond the scope of this report.

\subsubsection{Expansion characteristics}

Next we evaluate the expansion of the substorms from onset to the maximum of the events, measuring the MLT expansions ( $\triangle \mathrm{MLT})$ west and east from onset and the expansions in ILat ( $\Delta$ ILat). We don't evaluate the absolute values of these expansion locations because of the large variation in the onset locations (Fig. 4a). We then compare the expansion characteristics with those obtained from isolated substorms (Gjerloev et al., 2007). While such comparisons may not

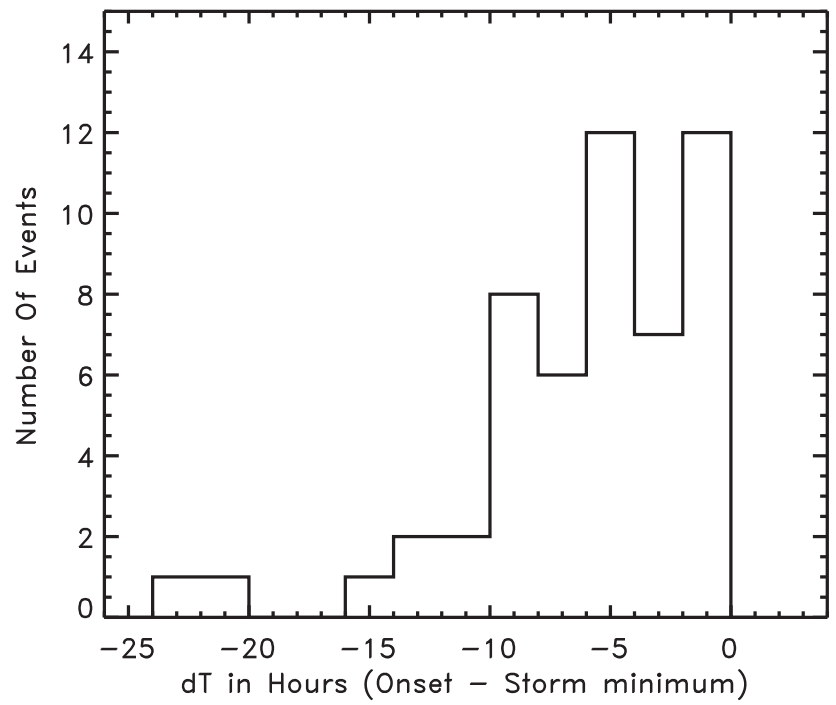

Fig. 7a. Histogram of the number of substorm onsets during main phase development relative to the time of Sym-H minimum $(\Delta \mathrm{UT})$ (after Wu et al., 2004, Fig. 4).

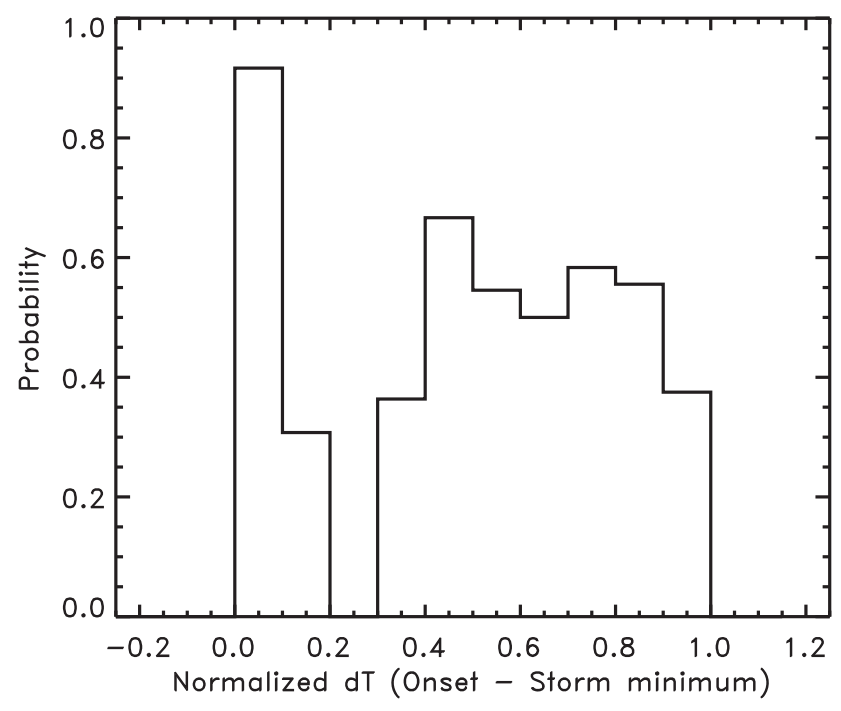

Fig. 7b. Histogram of the number of substorm onsets during main phase development as a function of normalized storm time.

all be quantitatively appropriate because of the differences in the gross features of the two sets of events, they do help reveal the differences of auroral activity under the two different conditions.

Figure 8 contains a histogram of the expansions in MLT for all the storm-time events with localized onsets (46), the left figure for westward expansion, the right figure for eastward expansion. The westward expansion was measured at the furthermost westward brightening of the aurora. The typical expansion was almost two hours westward in MLT, and the few bulge-type events lay well within the total 
Table 2. Median parameters comparing substorms during main phase development with isolated substorms.

\begin{tabular}{lcc}
\hline Characteristic & $\begin{array}{c}\text { Storm-time } \\
\text { substorms }\end{array}$ & $\begin{array}{c}\text { Isolated } \\
\text { substorms }\end{array}$ \\
\hline Onset location & 23.5 & 22.7 \\
$\quad$ MLT (hours) & 62.5 & 67.0 \\
$\quad$ ILat (degrees) & 15 & 30 \\
\hline Expansion phase (minutes) & & \\
\hline MLT expansion & -1.8 & -2.2 (bulge) \\
$\quad$ West end (hours MLT) & +3.9 & -0.7 (oval) \\
$\quad$ & +3.0 \\
$\quad$ East end (hours MLT) & 1.5 & 3.0 \\
Poleward ILat expansion & 1.0 & $\sim 0$ est. \\
$\quad$ West end (degrees) & & \\
East end (degrees) & +7.5 & -4.0 \\
(ILat expansion at MLT of maximum width & +8.2 & -2.75 \\
$\quad$ Poleward boundary & & \\
Equatorial boundary &
\end{tabular}
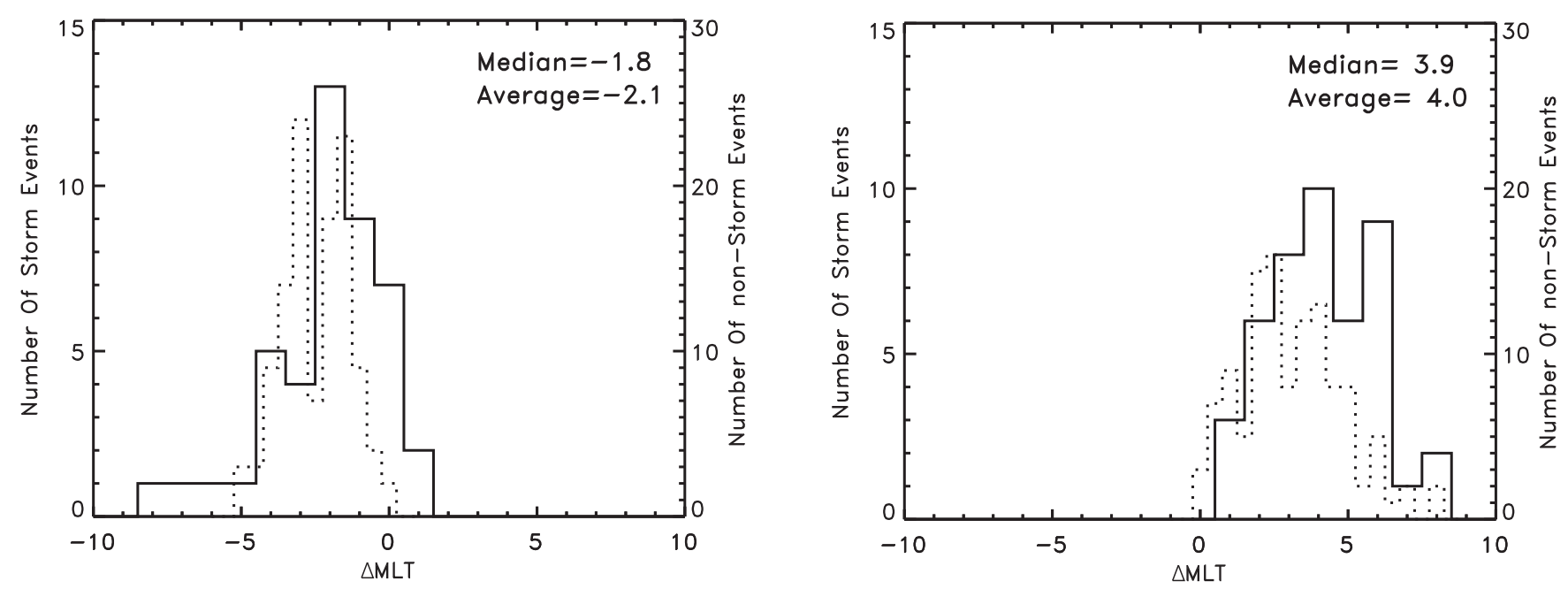

Fig. 8. Histogram of the number of substorms as a function of expansion from a localized onset to the maximum expansion in $\Delta$ MLT, westward expansion on the left, eastward expansion on the right. Superimposed are similar histograms for isolated substorms (dotted lines), the west end of the bulge, or surge head (left), and the east end of the oval aurora (right) (from Gjerloev et al., 2007).

distribution, though their median $(-2.5 \mathrm{~h})$ was slightly larger (not shown). The distribution has several events with large westward expansions. These are the dusk events, an example of which appears as Fig. 3g. During isolated substorms, the western-most expansion was the west end of the surge/bulge region, whose distributions are also shown in Fig. 8 (left) (from Fig. 9, Gjerloev et al., 2007). The median expansion was $-2.2 \mathrm{~h}$ MLT, larger in MLT than the median for all the events during storm development $(-1.8 \mathrm{~h})$ in spite of not having comparable "dusk events". On the other hand, the western end of the oval aurora during isolate substorms (see Fig. 10, Gjerloev et al., 2007), which was almost always less than the western end of the bulge, showed a median expansion of only $-0.7 \mathrm{~h}$ MLT west, considerably less than the typical expansion of the storm-time substorms. Thus we find that the westward expansions of storm-time substorms are typically different than the expansion of isolated substorms, much larger than the oval aurora, but smaller than the bulge aurora. We list the median values in Table 2.

Figure 8 (right) contains the eastward expansions for all the events that expanded from a localized onset. The magnitudes of the eastward expansions were typically about twice as large as the westward expansions, with a median of $3.9 \mathrm{~h}$. The few bulge-type events showed considerably 

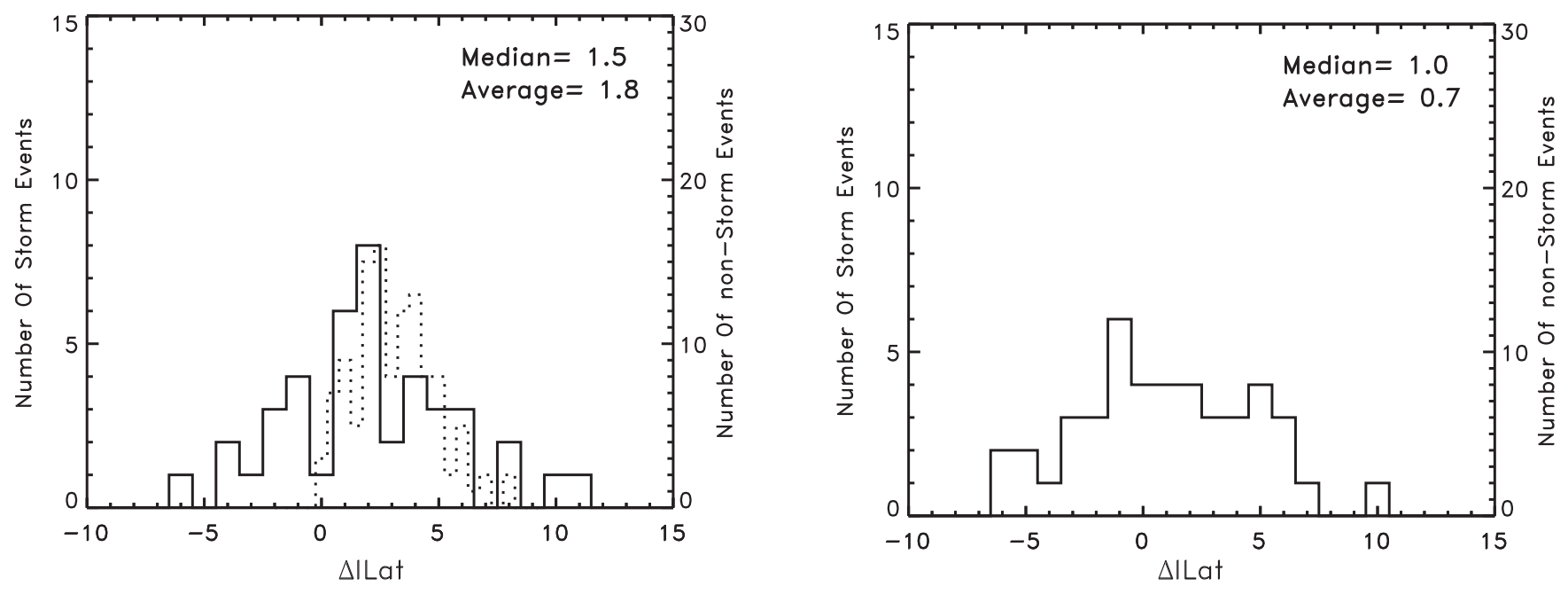

Fig. 9. Histogram of the number of substorms as a function of expansion from a localized onset in $\Delta$ ILat, at the west extremity of the auroral events (left) and at the east extremity (right). Superimposed are similar histograms (dotted lines) for isolated substorms, the west end of the surge head (left) and the east end of the bulge (right) (from Gjerloev et al., 2007).

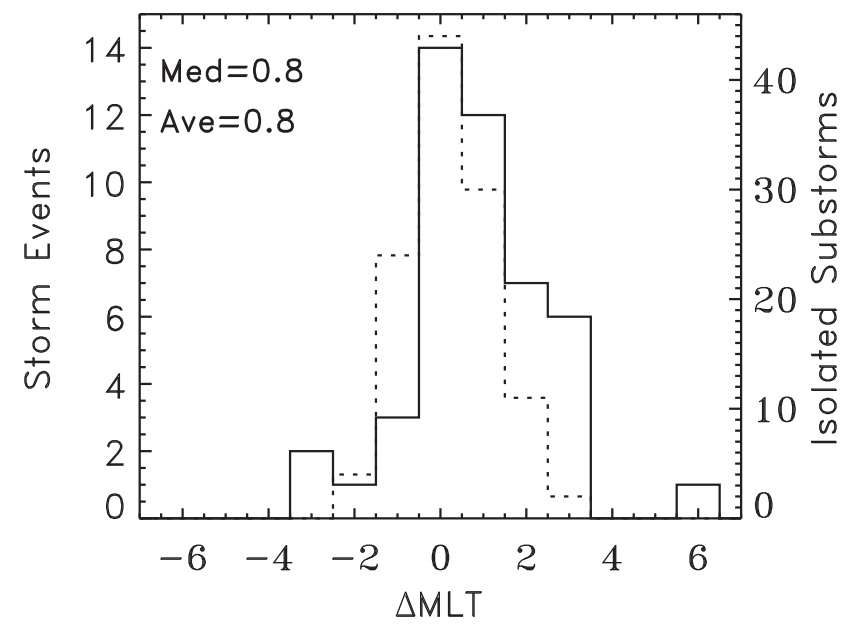

Fig. 10. Histograms of the differences in MLTs of the maximum expansions compared with the MLTs of onsets for the storm-time substorms (solid lines) and for the isolated substorms (dotted lines).

less expansion (not shown). This eastward expansion of the storm-time substorms was typically an oval expansion, more like the eastward expansion of the oval aurora during isolated substorms. When we compare in Fig. 8 (right) these eastward oval expansions we find the medians for stormtime substorms to be almost an hour of MLT further east, 3.9 vs. $3.0 \mathrm{~h}$. On the other hand, the expansion of the east end of the bulge for isolate substorms was considerably smaller, $2.5 \mathrm{~h}$ MLT (not shown), even smaller than the few bulge-type events during storm main phase development ( $3.0 \mathrm{~h} \mathrm{MLT).}$

These comparisons of the end locations of the oval auroras in $\triangle$ MLT from the onset locations give an impression that besides an overall expansion from the onset region there is superposed typically a larger eastward drift of the precip- itation region during the main-phase substorms than during isolated substorms. This is especially noteworthy considering that the expansion times are typically much shorter for storm-time substorms (see Table 2 for summary of expansions).

Similarly, in Fig. 9 (left), we plot the poleward expansion ( $\triangle \mathrm{ILat})$ at the west end of substorms during storm development. The distribution is very broad, with a considerable number showing equatorward motions (negative values). The few quasi bulge-type events generally showed a large poleward expansion. In contrast, expansion of the west end of the isolated substorms (superimposed in Fig. 9) was never equatorward, and the median was twice as large (Table 2). This quantitatively confirms our visual inspection of the images that the storm-time substorms do not show the rise of a surge out of the oval aurora. Thus the apparent rise of the surge/bulge out of the oval aurora is due to two factors, an actual rise in latitude and a MLT separation of the surge to the west of the oval aurora. Note that this MLT separation could never be observed in any of the oval expansion events (Fig. 3b-d), the dominant type of storm-time event, because it would require a bifurcation of the event.

The median of the latitude expansion of the east end of the storm events (Fig. 9, right) was small, with almost half the expansions equatorward. Within measurement accuracy, none of the bulge-type expanded equatorward. No measurements of this parameter were made for isolated substorms for comparison, but it was noted in Gjerloev et al. (2007) (see their Fig. 15) that there was little movement in latitude of the east end of the oval aurora during expansion, consistent with the east end of storm-time substorms. This common trait adds evidence that the storm time substorms are primarily oval aurora events. 

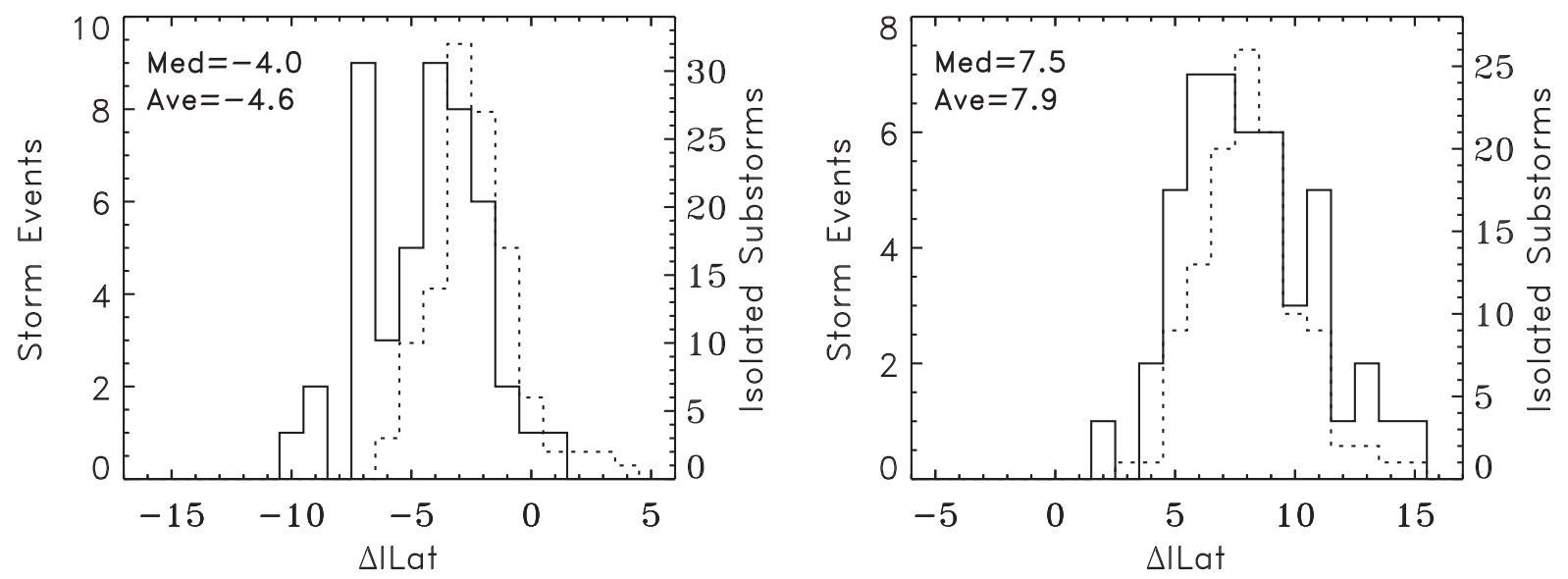

Fig. 11. Expansion of storm-time substorms at the MLT of maximum width with isolated events superposed (dotted lines), equatorward on the left, poleward on the right.

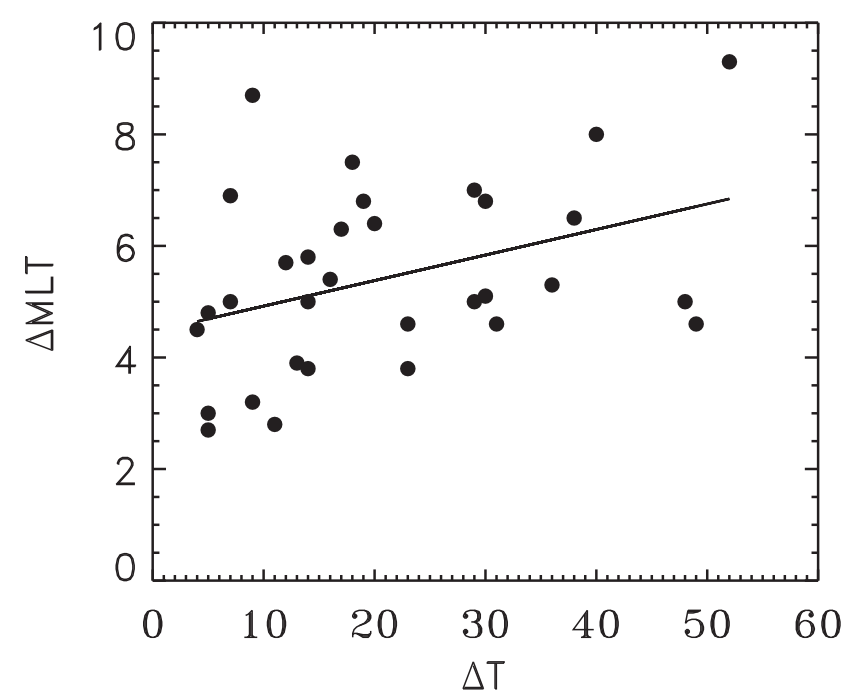

Fig. 12. Length in MLT of the type of substorms illustrated by the images labeled b, c and d in Fig. 3 as a function of development time for the substorm. Straight line is a least squares fit.

Finally we compare the $\Delta$ ILat expansions of the emissions for those substorms with localized onsets to give a measure of the latitude extent of expansion and another comparison with the expansion of isolated substorms. We must first ask where to make this measurement, since we note in the examples in Fig. 3 that the maximum expansion is not necessarily near the MLT of the onset. While Gjerloev et al. (2007) noted that the maximum expansion for isolated substorms was close to the onset MLT, we cannot assume that stormtime substorms have this characteristic. Figure 10 contains a histogram of the differences in MLTs of the maximum expansions compared with the MLTs of onsets for the storm-time substorms. We should point out that selecting the MLT of the maximum expansion cannot be done very accurately, but we are just looking for statistical trends. While there is a clustering of points around $\triangle \mathrm{MLT}=0$, there are many scattered in the positive (eastward) direction, up to $3 \mathrm{~h}$. The median change is about $0.4 \mathrm{~h}$. This would indicate that we should make the latitude expansion measurements at the MLT of the maximum width of the expanded emissions rather than at the onset MLT. For comparison we also show in Fig. 10 a histogram for the same measurement for isolated events. The distribution is fairly symmetric around $0 \mathrm{~h}$ with a median of about 0.1 , confirming the observation of Gjerloev et al. (2007). For storm-time substorms about $50 \%$ of the locations of maximum expansion were within $1 \mathrm{~h}$ of onset whereas about $70 \%$ of the isolated substorms were so clustered. This measurement complements those of the expansion measurements of the west and east ends of the expanded emission regions discussed above, again indicating a trend for an apparent eastward drift of the region of emissions compared to isolated substorms.

Figure 11 (left) contains a histogram of the equatorward expansions of the emissions from the ILat of onset at the location of maximum width for storm-time events. The median expansion is shown in Table 2. The superposed histogram for isolated events shows a smaller expansion, with the median listed in Table 2. Similarly Fig. 11 (right) contains the same types of data for the poleward expansions with the medians shown in Table 2. We find that the poleward expansion at the maximum width is larger for isolated substorms, but the equatorward expansion is larger for storm-time substorms, with storm-time events showing a slightly larger total expansion. The poleward expansion is about twice the amount as the equatorial expansion for storm-time events, but three times the amount for isolated events.

This analysis of the latitude expansion of storm-time substorms versus isolated substorms indicates that the stormtime substorms start at lower latitude and expand less in the poleward direction but more in the equatorial direction 
than the isolated substorms, keeping the expansion closer to the original auroral oval. The larger poleward expansion of the isolated substorms gives them their bulge shape and the rather straight poleward boundary seen in the images. The inability of the isolated substorms to expand much equatorward results in the total latitude expansions for the two types of substorms to be about the same.

In summary, we have compared the expansion characteristics of the extremities of the substorms emission regions and of the centers in $\triangle \mathrm{MLT}$ and $\triangle \mathrm{ILat}$ of storm-time substorms with isolated substorms. In all cases these comparisons indicate that the storm-time substorms show the characteristics of an expanding auroral oval rather than the rising of a bulge out of the auroral oval.

\section{Discussion}

\subsection{Selection of events}

The selection of substorms during the development of the magnetic storm main phase was more difficult than the selection of isolated substorms. For the isolated substorm study we used only bulge-type events, discarding any that did not have the characteristics of the classical Akasofu-type (1964) event. That study had 116 substorms, with about 20 other events discarded that did not display the classical characteristics. We encountered very few events that were uncertain to include because of their weak intensity. Thus the classical auroral substorm was by far the predominant isolated auroral event during non-magnetic storm periods, which justifies using that type of auroral display for comparison with storm-time substorms. As in this study, other events were also discarded due to contaminating sunlight or poor aspect.

We tried to keep the selection criteria as consistent with the isolated substorms criteria as possible (see Gjerloev et al., 2007, for discussion). However, we did not eliminate any particular auroral emission form like we did for the isolated substorms, since there was no particular form with a high percentage of occurrences. As mentioned in the Selection of Events, we did not include the many weak and short-lived optical brightenings during the magnetic storm main phases that we found.

We have also evaluated the impact of the color scales used in the images. A noticeable difference between isolated and storm-time events is the typical intensity. The survey images we used contained a color scale to 45 counts/pixel for the isolated substorms, but 100 counts/pixel for the stormtime events. This factor of two increase indicates that the storm-time events were roughly twice as bright as the isolated events, since the measured brightness in $\mathrm{kR}$ of the aurora within the wavelength interval of measurement is linear with the count rate. Even then, a few saturated the images, requiring an even larger scale to evaluate the structure of the event. To verify that we were not missing a type of event not categorized in Fig. 3 because of its lower intensities, we changed the counts/pixel scale to 50 for one storm. We found one clear additional event that started with a local onset, expanded in four to five minutes, and decayed. It did not contain a surge, bifurcate, or display a straight poleward boundary as for isolated substorms. It would be categorized as a "blob" (see Fig. 3b). Thus we conclude that the typical auroral event during storm main phase development is over twice as bright as isolated substorms.

The study by Lui et al. (2000) gives credence to our approach of ignoring small events. They obtained the probability distribution in spatial size and power of the auroral output from the magnetosphere system for all scale sizes, from $10^{3}$ to almost $10^{7} \mathrm{sq}$. km, separated into quiet time and substorm time intervals. They found a power law in the probability distribution during quiet times, but the power law for substorm times (including one magnetic storm) held only to about $5 \times 10^{4} \mathrm{sq}$. km, followed by a broad maximum (and peak in the dissipation power) to their largest events. They interpreted the power law distributed events as bursty, internal (localized) relaxations of the systems, consistent with simple avalanche (sandpile) models of the system, whereas the large events were interpreted as global reconfigurations. Our small events, such as shown in Fig. 3b, contained an area of about $10^{6} \mathrm{sq} . \mathrm{km}$, and the statistics of isolated substorms (Gjerloev et al., 2007, Figs. 11-13) also indicate at least this size range. Thus our events, both isolated substorms and main phase substorms, lie well into their class of global reconfigurations. While small events that we did not include may also have been of the types involving global reconfiguration, the only impact of not including them would be in our statistics of expansion, where the expansion times and spatial extent may be missing events at the lower ends of the distributions (Figs. 6, 8, 9 and 11).

Of the 12 substorms that did allow the measurement of the west and east ends of a possible surge/bulge, only two had all the primary characteristics of the isolated substorm (compare Fig. 3a with Fig. 2). Four did not expand from a spot, six did not show a brightened surge head, four did not bifurcate and four did not show a straight poleward boundary, indicative of a lack of a bulge that expands the poleward boundary near the middle of the event. Thus, considering all 54 events, we can conclude that seldom do the optical features of auroral brightenings during the development of the main phase of a magnetic storm show the characteristics of an isolated substorm.

While there were a sufficient number of storm-time events to perform this analysis, there was an insufficient number to yield distributions of the various parameters that could be mathematically represented (e.g., by Gaussian distributions) for quantitative comparisons as we did in the statistical analysis of isolated substorms (Gjerloev et al., 2007). Note in the figures that the average values deviated considerably in some cases from the medium values. Thus, in the section on expansion characteristics we worked primarily with medians 
in the distributions, which were adequate indicators of the behavior of the emission regions.

\subsection{Interpretation of the measurements}

We have found that the optical emissions during storm-time substorms do not display the same types of characteristics as seen during isolated substorms. The differences include:

1. onsets at considerably lower latitudes;

2. onsets at later local times;

3. much shorter expansion phases;

4. greater intensities by a factor of two;

5. lack of a surge/bulge;

6. lack of bifurcation;

7. seldom a straight poleward boundary;

8. smaller poleward expansion but larger equatorward expansion;

9. indications of an eastward drift of the expanding emission region;

10. larger variation in shapes and sizes in contrast to the classical auroral substorm.

1 and 2: The first two items could be attributed to a more distorted magnetospheric topology during storm development due to the strengthening of the ring current and the convection electric field than during isolated substorms. The onset latitudes show a displacement equatorward of about $0.1^{\circ}$ per $\mathrm{nT}$ for a Sym-H decrease from 0 to $-120 \mathrm{nT}$, where Sym-H was measured at time of substorm onset (Fig. 5b). This is almost three times the rate of decrease in latitude of the center of the westward electrojet current as a function of Dst as reported by Feldstein et al. (1997). The three largest events could indicate a limit to this equatorward offset. Besides the distortion of the magnetosphere, the higher $\mathrm{E}$ field magnitudes measured in the magnetosphere during high $\mathrm{Kp}$ would drive plasma deeper into the magnetosphere (Rowland and Wygant, 1998).

The clear trend towards lower latitudes of the onset location as a function of ring current strength shown in Fig. 5b extends the concern expressed by Gonzalez (1994) regarding the accuracy of classical auroral indices in representing the magnitude of a substorm during great storms to any magnetic storm. Feldstein et al. (1994) observed that the peak in latitude of the electrojet magnetic perturbation during the latter part of the expansion phase is at lower latitudes than most of the traditional index stations. By using subauroral station magnetograms, they built a corrected $\mathrm{AE}$ index, which during storms appeared to be twice as large as the traditional one.
The dependence of the onset location on Sym-H (Fig. 5b) explains the tail to $55^{\circ}$ latitude in the histogram of the onset distribution in Fig. 2b of Frey et al. (2004), since their onset selections were independent of magnetic activity, such as indicated by Sym-H. Their distribution shows the same extent of the distribution of onset points as shown in Fig. $4 \mathrm{c}$ for storm-time events. In contrast there is no low latitude tail in the distribution of onsets for isolated substorms, which cuts off at $62^{\circ}$ degrees, near the middle of the storm-time distribution.

3 and 4: The shorter development time for substorms during ring current development than for isolated substorms is quite remarkable (Fig. 6). Could it be that the short development time does not allow enough time for the bulge to rise out of the oval to bifurcate and, therefore, evolve into a classical substorm? We suggest not, for two reasons. First, the expansion size in ILat for both types of events is comparable, so there seems no temporal impediment for a bulge to rise out of and separate itself from the oval aurora. Second, if we lump together just the substorms with more restricted oval brightenings (forms b, c and d in Fig. 3), which seem to have comparable latitudinal characteristics, we do find some dependence in the magnetic local time length on expansion time (Fig. 12). Thus, again, one would expect bulge-type events to be able to develop at least for the longer expansion time substorms.

The factor of two greater intensities and shorter development times of the emissions indicate that the electron precipitation mechanism for the storm-time events is a more intense and dynamic mechanism even than for the electron precipitations in the surge region of isolated substorms (Fujii et al., 1994). The greater precipitation intensities will result in highly enhanced conductances, possibly exceeding 100 mhos, perhaps allowing larger currents to dissipate energy at a higher rate and thereby affecting the time it would take to deplete the magnetospheric source.

Storm-time coverage by the images during the 16 storms was $98 \mathrm{~h}$. With a total of 54 substorms, that gives an average of about $2 \mathrm{~h}$ between substorm onsets. With a median substorm expansion duration of something like $15 \mathrm{~min}$ or less, a substorm expansion is not occurring most of the time during the main phase development. Thus one must question whether substorms in any form play an important role in storm main phase development.

5, 6 and 7: Probably the most significant characteristics that differentiate the storm-time substorms from isolated substorms are the lack of a surge/bulge and bifurcation of the aurora. These features are characteristics of the existence of a substorm current wedge, the ionospheric portion of the three-dimensional current system coupling the magnetosphere with the ionosphere and indicative of unloading energy that was stored in the tail. Instead, we find that the storm-time events appear more as brightenings of the auroral oval, raising the question of where a Harang discontinuity (or region; see Gjerloev and Hoffman, 2001) would lie. 
The straight-line polar boundary of the emissions characterizing the isolated substorm as especially seen in the original images is merely a manifestation of the existence of a classical bulge. Since the maximum poleward expansion is much larger than the latitudinal expansion near the ends of the emission region, the shape of the poleward boundary on the curvature of the earth gives the impression of a straight line. Thus the lack of a straight-line polar boundary implies the lack of a bulge.

8: The smaller poleward expansion but larger equatorial expansion results in an emission region more closely related spatially to the original auroral oval. (Note: all onset locations lay within the pre-onset auroral oval.) This can be interpreted as an indication of an oval brightening and not a classical substorm brightening which typically has the brightest intensities towards the poleward boundary.

9: The comparisons of the end locations of the emission regions in $\triangle \mathrm{MLT}$ from the onset locations as well as the displacement of the MLT of the maximum width away from the onset MLT give an impression that besides an overall expansion from the source region there is superposed typically a larger eastward drift of the source region of precipitation during the main phase development than during isolated substorms. This is consistent with the finding by Rowland and Wygant (1998) of an increasing electric field in the inner magnetosphere as a function of magnetic activity (Kp).

10: Gjerloev et al. (2007) developed a very important analysis tool in the ability to normalize each different substorm emission region to an average emission region with a very high correlation coefficient between the emission intensities of each substorm to the average. We could attempt these normalizations for only a small fraction of the storm-time events because we could not select the critical points as we did with the isolated events (Fig. 1 in Gjerloev et al., 2007). This means that the distribution of the emission intensities over the emission region was unlike the distribution of isolated substorms. This result is supported by the recent work of Kornilova and Kornilov (2009) who analyzed the spatialtemporal dynamics at micro- and meso-scales of auroras during the main phase of magnetic storms using TV observations. They concluded that indeed substantial differences do exist between the classical substorm and auroras during the magnetic storm main phase with the scenario of auroral development depending on many factors.

\section{Conclusions}

We sought to answer the question: Are there optical differences between storm-time substorms and isolated substorms? The answer is clearly yes.

Using images from the Earth Camera on the Polar spacecraft (Frank et al., 1995), we compared the large-scale optical emission features that were displayed by substorms occurring during 16 expansion phases of magnetic storms with the features of isolated substorms. The comparison used two techniques, visual inspection and statistical comparisons. The comparisons were based on the common characteristics seen in isolated substorms that were initially identified by Akasofu (1964) and quantified by Gjerloev et al. (2008).

The primary differences between the two sets of events are the lack of a surge/bulge and a bifurcation of the aurora in the storm-time substorms. These features are characteristics of the existence of a substorm current wedge, the ionospheric portion of the three-dimensional current system coupling the magnetosphere and ionosphere during isolated substorms. If this phenomenon does not exist during substorms occurring during magnetic storms, then the magnetosphere-ionosphere current system during the storm-time substorms must be different. The puzzle becomes more complex when we add the findings that the expansion times of storm-time substorms are like half the time for isolated substorms, but with the intensities of the optical emissions roughly twice those for isolated substorms. Several of the analyses suggest that the stormtime substorms are associated more closely with the auroral oval, at least spatially, and, therefore, with the plasma sheet dynamics during the main phase development.

If the auroral characteristics had been found common for the two types of events, then the electrodynamic characteristics of the classical substorm could be assumed to exist during storm-time substorms. However, since we did not find such a commonality, it would be presumptuous to assume similar electrodynamics. These results, though restricted to only one electrodynamic parameter, must call into question the widely held assumption that there is no intrinsic difference between storm-time substorms and classical isolated substorms.

Since the optical signatures we have analyzed are only one part of the electrodynamics of substorms, and primarily imply where the ionospheric conductances are enhanced, this interpretation of our comparisons needs confirmation by the analysis of other electrodynamic parameters. To date little analysis has been performed on the electrodynamic parameters at ionospheric altitudes during the main phase, or comparisons of the electrodynamics in the magnetosphere. Until these analyses are performed we caution the applicability of classical electrodynamic substorm phenomenology and terminology when interpreting and explaining storm-time substorm phenomena.

Acknowledgements. One of us (RAH) performed most of the work on this paper while on the emeritus program in the Heliophysics Science Division of Goddard Space Flight Center.

Topical Editor I. A. Daglis thanks two anonymous referees for their help in evaluating this paper. 


\section{References}

Akasofu, S.-I.: The development of the auroral substorm, Planet. Space Sci., 12, 276-282, 1964.

Akasofu, S.-I.: Polar and Magnetospheric Substorms, D. Reidel, Norwell, Mass., 1968.

Baumjohann, W., Kamide, Y., and Nakamura, R.: Substorms, storms and the near-earth tail, J. Geomag. Geoelectr., 48, 177185, 1996.

Chapman, S.: Earth storms: retrospect and prospect, J. Phys. Soc. Japan, 17, 6-16, 1962.

Feldstein, Y. I. and Starkov, G. V.: Dynamics of auroral belt and polar geomagnetic disturbances, Planet. Space Sci., 15, 209-229, 1967.

Feldstein, Y. I., Levitin, A. E., Golyshev, S. A., Dremukhina, L. A., Vestchezerova, U. B., Valchuk, T. E., and Grafe, A.: Ring current and auroral electrojets in connection with interplanetary medium parameters during magnetic storm, Ann. Geophys., 12, 602-611, 1994 ,

http://www.ann-geophys.net/12/602/1994/.

Feldstein, Y. I., Grafe, A., Gromovva, I. I., and Popov, V. A.: Auroral electrojets during geomagnetic storms, J. Geophys. Res., 102, 14223-14235, 1997.

Frank, L. A., Sigwarth, J. B., Craven, J. D., et al.: The visible imaging system (VIS) for the Polar spacecraft, Space Sci. Rev., 71, 297-328, 1995.

Frank, L. A. and Sigwarth, J. B.: Transient decrease of Earth's far ultra-violet dayglow, Geophys. Res. Lett., 24, 2423-2426, 1997.

Frey, H. H., Mende, S. B., and Angelopoulos, V.: Substorm onset observations by IMAGE-FUV, J. Geophys. Res., 109, A10304, doi:10.1019/2004JA010607, 2004.

Fujii, R., Hoffman, R. A., Anderson, P. C., Craven, J. D., Sugiura, M., Frank, L. A., and Maynard, N. C.: Electrodynamic parameters in the nighttime sector during auroral substorms, J. Geophys. Res., 99, 6093-6112, 1994.

Germany, G. A., Torr, M. R., Torr, D. G., and Richards, P. G.: Use of FUV auroral emissions as diagnostic indicators, J. Geophys. Res., 99, 383-388, 1994.

Gjerloev, J. W., and Hoffman, R. A.: Height-integrated conductivity in auroral substorms: 1. Data, J. Geophys. Res., 105, 215-226, 2000.

Gjerloev, J. W. and Hoffman, R. A.: The convection electric field in auroral substorms, J. Geophys. Res., 106, 12919-12931, 2001.

Gjerloev, J. W. and Hoffman, R. A.: Currents in auroral substorms, J. Geophys. Res., 107, 1435, doi:10,1029/2001JA000194, 2002.

Gjerloev, J. W., Hoffman, R. A., Sigwarth, J. B., and Frank, L. A.: Statistical description of the bulge-type auroral substorm in the far ultraviolet, J. Geophys. Res., 112, A07213, doi:10.1029/2006JA012189, 2007.

Gjerloev, J. W., Hoffman, R. A., Sigwarth, J. B., Frank, L. A., and Baker, J. B.: Typical auroral substorm: A bifurcated oval, J. Geophys. Res., 113, A03211, doi:10.1029/2007JA012431, 2008.

Gonzalez, W. D., Joselyn, J. A., Kamide, Y., Kroehl, H. W., Rostoker, G., Tsurutani, B. T., and Vasyliunas, V. M.: What is a geomagnetic storm?, J. Geophys. Res., 99, 5771-5792, 1994.
Kamide, Y.: Is substorm occurrence a necessary condition for a magnetic storm?, J. Geomag. Geoelectr., 44, 109-117, 1992.

Kamide, Y., Sun, W., and Akasofu, S.-I.: The average ionospheric electrodynamics for the different substorm phases, J. Geophys Res., 101, 99-110, 1996.

Kamide, Y., Baumjohann, W., Daglis, I. A., Gonzalez, W. D., Grande, M., Joselyn, J. A., McPherron, R. L., Phillips, J. L., Reeves, E. G., Rostoker, G., Sharma, A. S., Singer, H. J., Tsurutani, G. T., and Vasyliunas, V. M.: Current understanding of magnetic storms: storm-substorm relationships, J. Geophys Res., 103, 17705-17728, 1998.

Kan, J.: Storm-substorm relations workshop, EOS, 87, 234, 2006.

Kan, J. R.: Synthesizing a global model of substorms, Geophysical Monograph 64, p. 73-87, American Geophysical Union, 1991.

Kornilova, T. A. and Kornilov, I. A.: Spatial-temporal dynamics of auroras during the magnetic storm main phase, Geomag. Aeronomy, 49, 722-731, 2009.

Lui, A. T. Y., Chapman, S. C., Liou, K., Newell, P. T., Meng, C. I., Brittnacher, M., and Parks, G. K.: Is the dynamic magnetosphere an avalanching system?, Geophys. Res. Lett., 27, 911-914, 2000.

McPherron, R. L.: Growth phase of magnetospheric substorms, J. Geophys Res., 75, 5592-5599, 1970.

McPherron, R. L.: The role of substorms in the generation of magnetic storms, Magnetic Storms, Geophysical Monograph 98, American Geophysical Union, 1997.

Ohtani, S., Brandt, P. C., Mitchell, D. G., Singer, H., Nose, M., Reeves, G. D., and Mende, S.: Storm-substorm relationship: Variations of the hydrogen and oxygen energetic neutral atom intensities during storm-time substorms, J. Geophys. Res., 110, A07219, doi:10.1029/2004JA010954, 2005.

Rostoker, G., Akasofu, S.-I., Foster, J., Greenwald, R. A., Kamide, Y., Kawasaki, K., Lui, A. T. Y., McPherrron, R. L., and Russell, C. T.: Magnetospheric substorms - Definition and signatures, J. Geophys Res., 85, 1663-1668, 1980.

Rowland, D. E. and Wygant, J. R.: Dependence of the large-scale, inner magnetospheric electric fielded on geomagnetic activity, J. Geophys. Res., 103, 14959-14964, 1998.

Sheehan, R. E. and Carovillano, R. L.: Characteristics of the equatorward auroral boundary near midnight determined from DMSP images, J. Geophys Res., 83, 4749-4754, 1978.

Torr, M. R., Torr, D. G., Zukic, M., et al.: A far-ultraviolet imager for the international solar-terrestrial physics mission, Space Sci. Rev., 71, 329-383, 1995.

Tverskaya, L. V., Tel'tsov, M. V., and Shkol'nikova, S. I.: Dynamics of the nightside auroral oval related to substorm activity during magnetic storms, Geomagn. Aeron., 29, 321-323, 1989.

Wu, C.-C., Liou, K., Lepping, R. P., and Meng, C.-I.: Identification of substorms within storms, J. Atmos. Terr. Phys., 66, 125-132, 2004. 